\title{
Towards Quantifying the Effects of Robotic Process Automation
}

\author{
Judith Wewerka \\ Institute of Databases and Information Systems \\ Ulm University \\ Ulm, Germany \\ 0000-0002-4809-2480
}

\author{
Manfred Reichert \\ Institute of Databases and Information Systems \\ Ulm University \\ Ulm, Germany \\ 0000-0003-2536-4153
}

\begin{abstract}
Robotic Process Automation (RPA) is the automation of rule-based routine processes to increase process efficiency and to reduce process costs. In practice, however, RPA is often applied without knowledge of the concrete effects its introduction will have on the automated process and the involved stakeholders. Accordingly, literature on the quantitative effects of RPA is scarce. The objective of this paper is to provide empirical insights into improvements and deteriorations of business processes achieved in twelve RPA projects in the automotive industry. The results indicate that the positive benefits promised in literature are not always achieved in practice. In particular, shorter case duration and better quality are not confirmed by the empirical data gathered in the considered RPA projects. These quantitative insights constitute a valuable contribution to the currently rather qualitative literature on RPA.
\end{abstract}

Index Terms-Robotic Process Automation, Quantify RPA Effects, Measure RPA, Monitor RPA Bots

\section{INTRODUCTION}

Robotic Process Automation (RPA) aims to automate processes by software bots mimicking human interactions [2]. In particular, RPA supports organizations with optimizing and implementing their business processes [21] or parts of these processes by exploiting automation opportunities. Consequently, expectations on the benefits introduced by RPA are high, although the value created by RPA projects is not granted [30]. Enterprises therefore crave for insights into the effects created by the implementation and introduction of RPA, particularly into whether or not the expected benefits can be actually achieved. In the following, implementation refers to the coding and testing of the RPA bot, whereas introduction considers the roll out and actual use of the bot.

Though the usefulness of implementing and introducing RPA is generally acknowledged by enterprise architects, concrete RPA effects are not sufficiently reported in literature. The benefits of RPA appear pervasive, but to the best of our knowledge there are no empirical evaluations confirming that RPA actually improves business processes. This lack of empirical evidence confirming RPA effects necessitates empirical studies for quantifying these effects. The term effects is used, as we do not want to solely focus on RPA benefits, but look at negative RPA effects as well.

This paper qualifies and quantifies the effects of twelve RPA projects (i.e., P01-P12) on the product engineering process of an automotive vendor. For this purpose, 14 interviews (i.e., I01-I14) were conducted to qualify RPA effects. Afterwards, RPA effects were quantified by questionnaires asking for performance indicators, e.g., speed or quality. The data were collected from professionals involved in the RPA projects and shall help to properly assess RPA effects. Note that the paper is less about offering a specific study for individual effects, but rather about presenting expected and achieved effects in twelve real-life projects in a knowledge-intensive domain.

\section{Methodology}

We derived relevant research questions (RQs). First of all, we investigated RPA projects in the domain of automotive engineering and tried to qualify the effects the involved stakeholders expected from the respective RPA initiative. This resulted in our first research question RQ 1: What effects should be achieved with RPA projects? Then, we investigated whether and how the occurrence of the respective effects can be measured. This was formulated in the second research question RQ 2: How is it currently measured whether or not the expected RPA effects are achieved? Based on RQ 2, we investigated, which measures are appropriate to quantify these effects. This led to the third research question RQ 3: Which measures provide information on the occurrence of the RPA effects? Finally, the last research question aimed to quantify the discovered effects in detail: RQ 4: Were the expected RPA effects achieved?

Our methodical approach is illustrated by Fig. 1. In particular, we wanted to consider insights from both literature and practice. Regarding the former, literature on RPA effects was systematically reviewed to answer RQ 1 - RQ 3 [29]. Regarding the latter, semi-structured interviews and a questionnaire were used. We conducted semi-structured interviews with seven RPA product owners and seven RPA creators to qualify the effects that shall be achieved with twelve RPA projects. An RPA product owner is the person responsible for the RPA project on the management side. An RPA creator, in turn, is the person programming the RPA bot. The interview guide was structured as follows: First, general information on the RPA project and the resulting RPA bot was gathered. Second, 


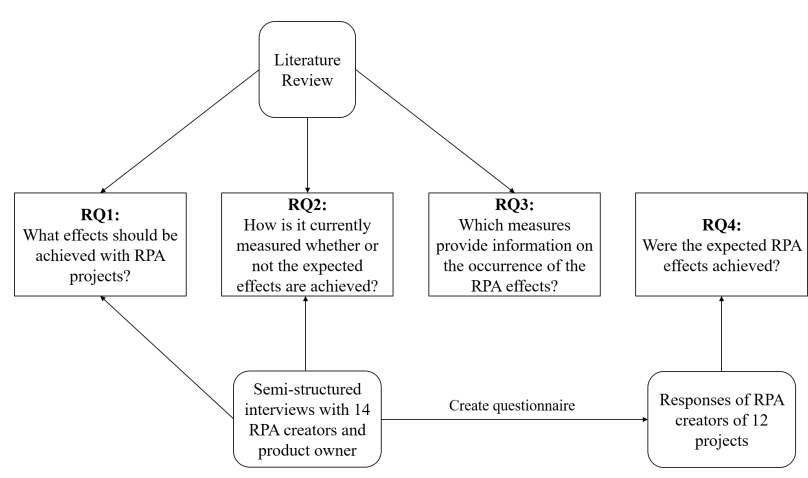

Fig. 1. Research Method.

TABLE I

OVERVIEW OF THE TWELVE RPA PROJECTS.

\begin{tabular}{c|c|l}
\hline Project & Interview & Bot description \\
\hline \hline P01 & I01 & $\begin{array}{l}\text { Bot downloads and uploads data into a system } \\
\text { for comparison. }\end{array}$ \\
\hline P02 & I02 & $\begin{array}{l}\text { Bot gathers data from different IT systems and } \\
\text { provides dashboards for engineers. }\end{array}$ \\
\hline P03 & I03, I13 & $\begin{array}{l}\text { Bot generates reports with data from different } \\
\text { systems for communication to the customer. }\end{array}$ \\
\hline P04 & I04 & $\begin{array}{l}\text { Bot archives old files according to a predefined } \\
\text { logic. }\end{array}$ \\
\hline P05 & I05 & Bot assigns tasks to the responsible employee. \\
\hline P06 & I06 & $\begin{array}{l}\text { Bot checks material orders and triggers the inter- } \\
\text { nal order process. }\end{array}$ \\
\hline P07 & I07 & $\begin{array}{l}\text { Bot calculates prices based on given information } \\
\text { and sends the result to the requester. }\end{array}$ \\
\hline P08 & I08 & $\begin{array}{l}\text { Bot reads data from Excel files and creates claim } \\
\text { reports. }\end{array}$ \\
\hline P09 & I09 & $\begin{array}{l}\text { Bot gets data from Excel files and creates com- } \\
\text { mercial invoices in the respective system. }\end{array}$ \\
\hline P10 & I10 & Bot exports and saves data for quality checks. \\
\hline P11 & I11 & $\begin{array}{l}\text { Bot checks whether an order is correct; if this is } \\
\text { not the case, it sends an email to the requester. }\end{array}$ \\
\hline P12 & I12, I14 & $\begin{array}{l}\text { Bot generates, stores, and compares data. Further- } \\
\text { more, it records process-related events to check } \\
\text { for business process compliance. }\end{array}$ \\
\hline
\end{tabular}

we asked for the effects expected from the RPA project. Finally, information on monitoring the bot was collected. Each interview lasted around 30 minutes and data was analysed using an inductive approach.

Based on the interview results we developed a questionnaire that surveyed data before and after introducing RPA (cf. Appendix). We measured improvements and deteriorations with the RPA introduction. The questionnaire was distributed to the RPA creators of the twelve projects. Note that the data retrieved with the questionnaire are estimations made by experts to the best of their knowledge, which constitutes a widely accepted approach [12].

The interviewees and participants of the questionnaire were selected from twelve different RPA projects in the area of product engineering in the automotive industry. Due to lack of space, the twelve software bots of the RPA projects cannot be described in detail. However, some background on the respective bot functions is provided in Table I.

\section{RESULTS}

\section{A. RQ 1: What Effects Should Be Achieved with RPA Projects?}

As a preparation step, a systematic literature review was performed [29]. Based on well-defined criteria, relevant literature on RPA was studied. The insights from literature on RPA effects are summarized in the following.

Based on this review, the effects expected from RPA projects can be divided into the ones on the enterprise and its business processes on one hand and the effects on enterprise staff on the other. Due to space limitations, we only consider the expected effects on the enterprise, which are mostly positive:

- Speed: Automated processes shall run faster and the average case duration (i.e., the time needed for processing the business case) shall become shorter. Accordingly, it is expected that more work can be accomplished with the same resources or full time equivalents (FTE) can be saved [1], [5], [7], [10], [13], [14], [17], [23], [26], [27], [30], [32].

- Availability: Most RPA bots are available 24/7 and instant access is granted. Moreover, RPA is highly scalable to meet varying intensity of demands [1], [4], [7], [13], [16], [19], [23], [24], [31], [33].

- Compliance: Processes executed by a bot become transparent and are documented in detail fostering compliance [13], [15]-[17], [19], [24], [31].

- Quality: RPA eliminates human errors, improves accuracy and data quality, and leads to higher customer satisfaction [4]-[7], [17], [19], [23], [24], [26], [27], [30], [31], [33].

Negative effects or limitations of RPA are seldomly reported in literature, e.g., [11] characterizes RPA solutions as workarounds and [2] and [10] emphasize that RPA constitutes a temporary solution. According to [3], there are software suites (e.g., special forensic software) not being compatible with current RPA solutions.

In the 14 conducted interviews (i.e., I01-I14), we asked RPA professionals, which effects they expected from their RPA projects. Most effects mentioned by the interviewees comply with the ones reported in literature. Overall, we discovered six different effects (FTE savings, improvement of result quality, faster processes, RPA as temporary solution, improvement of availability, and improvement of compliance). Moreover, no negative effects were mentioned. Table II summarizes the results. A "+" indicates that the person expected the effect to be positive in the RPA project, whereas a "-" indicates that the effect is not relevant. In the context of "RPA as temporary solution" a "+" indicates that the person expects RPA to be a temporary solution being replaced, e.g., by an IT interface, whereas a "-" emphasizes that the interviewee expects RPA to be a permanent solution. Note that interviewees from the same project, e.g., I03 and I13, might expect different RPA effects. 
TABLE II

EFFECTS MENTIONED IN THE INTERVIEW.

\begin{tabular}{|c|c|c|c|c|c|c|}
\hline Interview & FTE savings & $\begin{array}{l}\text { Improvement of } \\
\text { result quality }\end{array}$ & Faster process & $\begin{array}{c}\text { RPA as temporary } \\
\text { solution }\end{array}$ & $\begin{array}{l}\text { Improvement of } \\
\text { availability }\end{array}$ & $\begin{array}{l}\text { Improvement of } \\
\text { compliance }\end{array}$ \\
\hline I01 & + & + & & & + & \\
\hline I02 & & + & - & & & \\
\hline $\mathrm{I} 03$ & + & + & & & & \\
\hline I04 & + & + & & - & & \\
\hline I05 & + & & + & & + & \\
\hline I06 & + & & & & & \\
\hline I07 & + & & & & & \\
\hline I08 & - & & + & + & & \\
\hline I09 & + & + & - & & & \\
\hline I10 & + & & & - & + & \\
\hline I11 & + & & - & & & \\
\hline $\mathrm{I} 12$ & + & + & & & & + \\
\hline I13 & + & & + & & & \\
\hline I14 & + & + & & & & + \\
\hline
\end{tabular}

\section{B. RQ 2: How Is It Currently Measured Whether or Not the Expected RPA Effects Are Achieved?}

When studying current literature on measuring RPA effects and their occurrence, results are very scarce. Reference [19] indicates that "You need to track and monitor the effectiveness". Several papers emphasize the importance of monitoring the implemented bots [8], [19], whereas [9] and [23] suggest evaluating key performance indicators before and after implementing and introducing the RPA approach in order to measure actual improvements. No details on how to accomplish such measurements are given. According to [30] "results are not guaranteed". In [13], cost savings of $30 \%$ per process are achieved. Reference [31] emphasizes that cycle time is reduced from days to minutes and an accuracy of $99.99 \%$ can be accomplished.

Only few suggestions are made in respect to concrete measures for RPA effects, i.e., to measure

- quality improvements based on the number of mistakes made [25],

- speed of the RPA bot based on the number of transactions it performs in a certain time frame [1], [8], [23], [32],

- cost savings in terms of the number of saved FTE [8], [9], [23], [30],

- FTE savings by average numbers of staff and cases per staff per month [32].

Except in [1] and [32], no concrete numbers are provided on respective measures. To measure productivity, [1] observes that the mean case duration required when using RPA is 9 seconds less than without RPA and agents are able to handle $21 \%$ more cases with RPA than before. In [32], productivity is measured by the average number of cases per staff per month. After introducing RPA, productivity improves by over $1,051 \%$. The mean case duration is reduced from 360 minutes without RPA to 15 minutes with RPA in the first use case and from 120 minutes without RPA to 15 minutes with RPA in the second use case.
During the interviews, we investigated the situation in the RPA projects in the product engineering process. The interviewees were asked whether or not the RPA bot provided as a result of their project is monitored. Only five out of 14 confirmed such a monitoring of the bot. In detail, monitoring means that the RPA creators look at the errors made by the bot to properly react and to document the number of errors. Additionally, two interviewees monitor the case duration of the RPA bot. Most RPA professionals agreed that "the main thing is that the bot works properly".

\section{C. $R Q$ 3: Which Measures Provide Information on the Occur- rence of the RPA Effects?}

RQ 3 combines the results from the two preceding research questions. For every effect identified in the context of RQ 1, we either obtain a measure from RQ 2 or develop a new one. Each measure is taken before as well as after introducing RPA. Table III summarizes the effects and corresponding measures.

\section{RQ 4: Were the Expected RPA Effects Achieved?}

To answer RQ 4, we evaluated the twelve questionnaires filled by RPA experts. The measures proposed in Table III served as a basis for this evaluation.

Fig. 2 shows the FTE savings per RPA project (P01P12), calculated by the formula from Table III. Some projects achieve minor FTE savings (P03, P04, P08) in their business processes, only two of them save 1.43 FTE (P09, P12). All other have FTE savings between 0.2 and 0.6 FTE.

To assess the improvement of result quality [18], we evaluated the percentage of cases with error before and after introducing the RPA bot. A case with error is considered to be a case that does not produce the expected result and manual rework is necessary. Fig. 3 visualizes the percentage of cases with error before and after RPA introduction, as well as the percentage change. Accordingly, projects $\mathrm{P} 02, \mathrm{P} 04, \mathrm{P} 05$, and P09 are successful RPA introductions reducing the number of errors and improving quality. Some projects achieve slight improvements and the bot is at least as good as a human. 


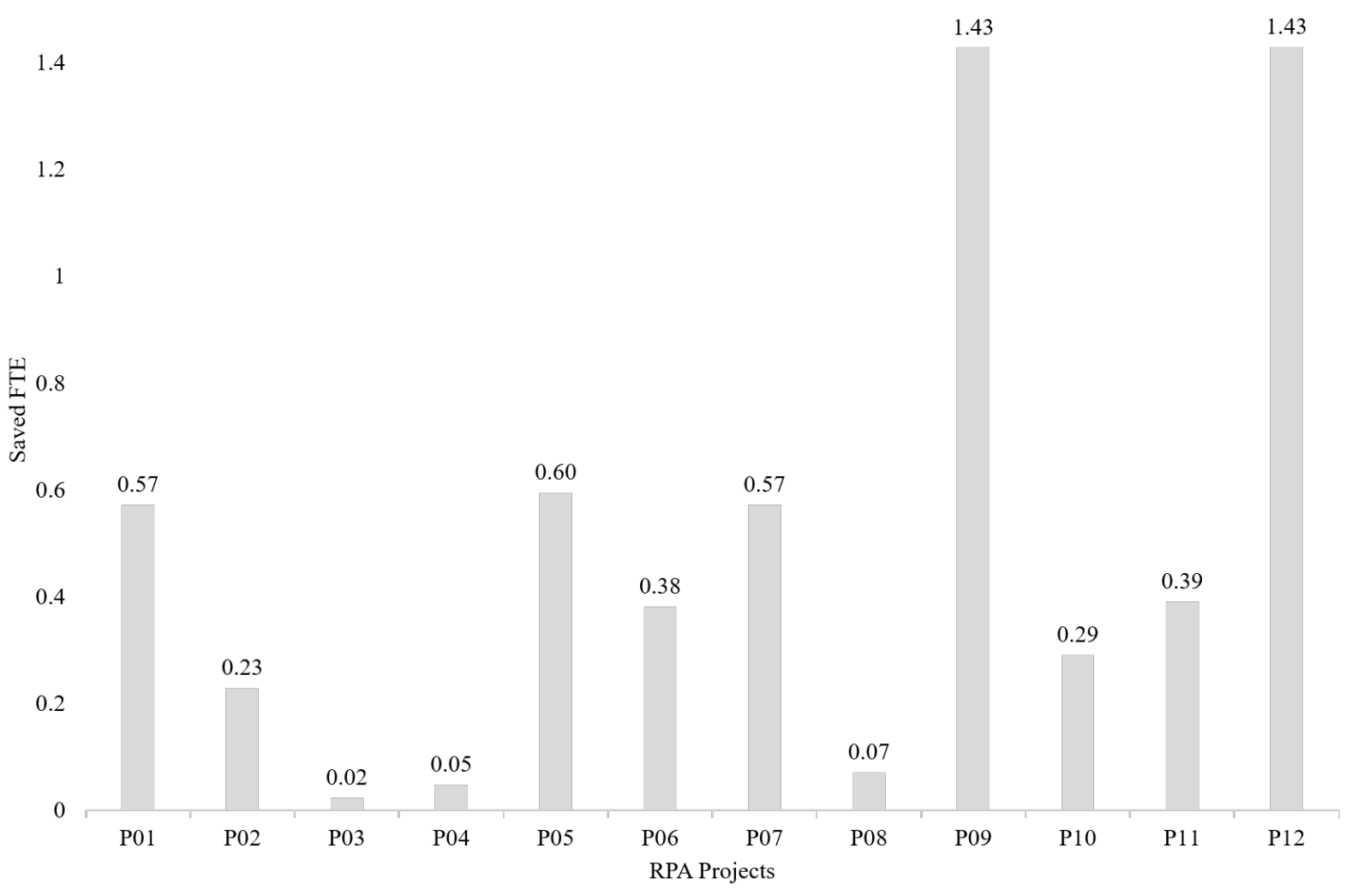

Fig. 2. FTE savings per project.

TABLE III

MEASURES FOR RPA EFFECTS.

\begin{tabular}{|c|c|c|}
\hline Effect & $\begin{array}{l}\text { Measure proposed } \\
\text { in literature }\end{array}$ & Developed measure \\
\hline FTE savings & $\begin{array}{l}\text { Cost savings [8], [9], } \\
{[23],[30]}\end{array}$ & $\frac{\# \text { cases per day } \times \text { minutes per case }}{\text { daily working time of employee }}$ \\
\hline $\begin{array}{l}\text { Improvement } \\
\text { of result quality }\end{array}$ & $\begin{array}{l}\text { Number of mistakes } \\
\text { [25] }\end{array}$ & $\begin{array}{l}\text { Percentage of cases with er- } \\
\text { ror }\end{array}$ \\
\hline Faster process & $\begin{array}{l}\text { Number of cases }[1] \text {, } \\
{[8],[23] \text {, }} \\
\text { mean case duration } \\
{[1],[32]}\end{array}$ & - \\
\hline $\begin{array}{l}\text { Temporary so- } \\
\text { lution }\end{array}$ & - & $\begin{array}{l}\text { Polar question: RPA as tem- } \\
\text { porary solution }\end{array}$ \\
\hline $\begin{array}{l}\text { Improvement } \\
\text { of availability }\end{array}$ & - & $\begin{array}{l}\text { Polar question: unexpected } \\
\text { downtime of the bot }\end{array}$ \\
\hline $\begin{array}{l}\text { Improvement } \\
\text { of compliance }\end{array}$ & - & $\begin{array}{l}\text { Percentage of cases with } \\
\text { compliance issues }\end{array}$ \\
\hline
\end{tabular}

Regarding P07, P08, and P12, severe deteriorations with up to 24 times more cases with error than before occur with the implementation and introduction of the RPA bot.

To measure whether the process is faster, the number of cases per day and the mean case duration before and after RPA introduction were evaluated. For the investigated projects, the number of cases does not change after introducing the bot. Apparently, all cases were already handled before the RPA introduction. Therefore, Fig. 4 displays the mean case duration in minutes for the twelve projects before and after RPA introduction and the percentage change. Only one project achieves a clear reduction of the case duration (P05). Five projects achieve a bit faster process and the process supported by the RPA bot takes between $50 \%$ to $75 \%$ of the manual process (P02, $\mathrm{P} 06, \mathrm{P} 07, \mathrm{P} 10$, and $\mathrm{P} 12)$. The other processes deteriorate and the process becomes slower than before. Interestingly, two projects (P03 and P08) significantly slow down the process due to the introduction of the RPA bot.

For seven projects, RPA is seen as a temporary solution, contrary to five projects considering RPA as long-term solution (cf. Fig. 5).

Improvement of availability is achieved in every project. There are no unexpected downtime of the bot. Therefore, the bot is virtually available $24 / 7$ compared to a human worker with fixed working hours and absence times.

As none of the projects had compliance problems before implementing and introducing the RPA bot, improvement of compliance is not measurable.

\section{DISCUSSION}

The presented results enable us to answer the RQs. In the following, the results are discussed and interpreted along the RQs using the insights gained through accompanying the 


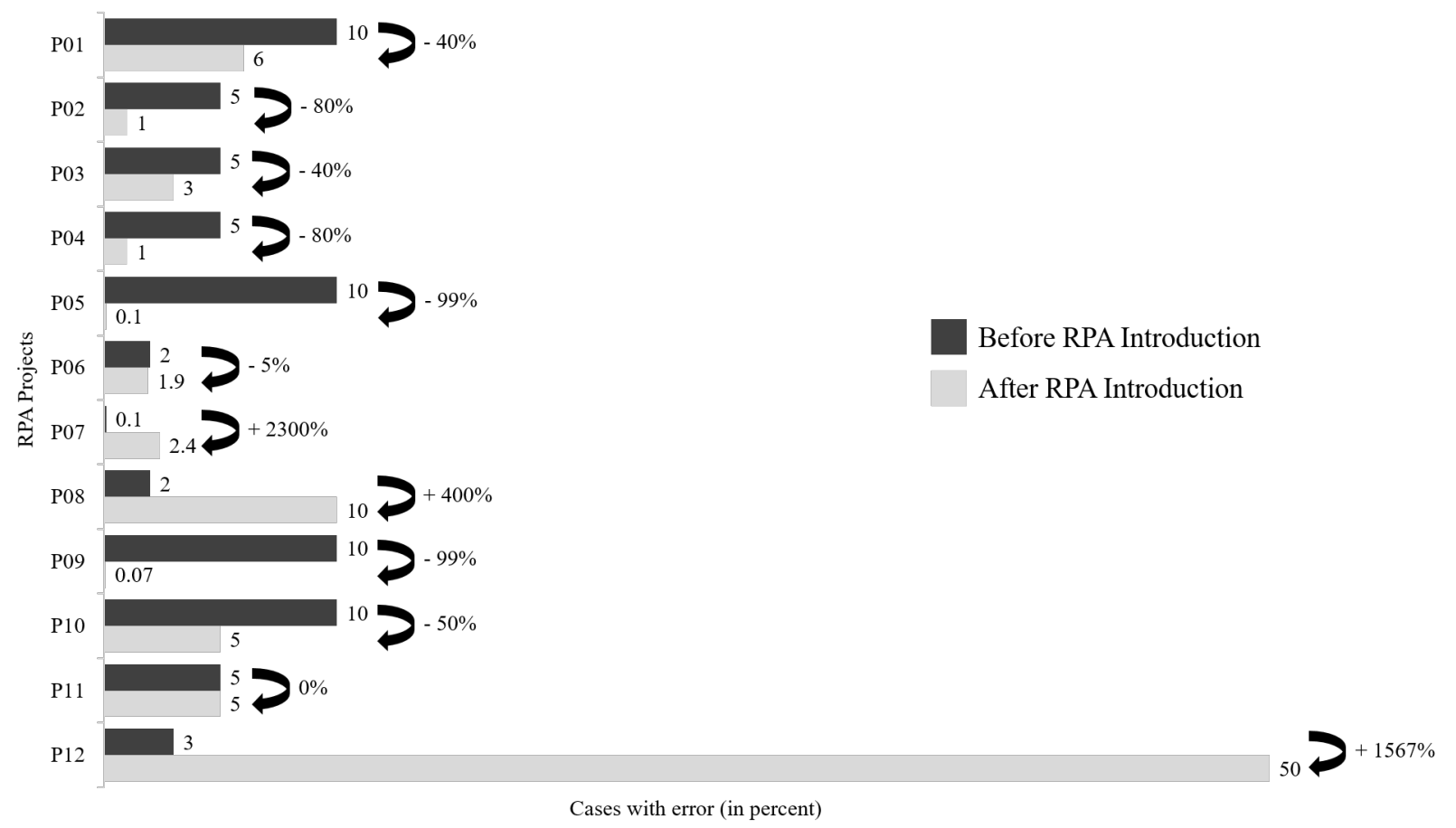

Fig. 3. Percentage of cases with error per project before and after RPA introduction and percentage change.

twelve projects for one year. The data was gathered over a period of six months after the introduction of the respective RPA bot.

Comparing the results of the literature review and the interviews for RQ 1, all effects considered as important in practice are covered by literature, although granularity differs: In literature, the aspect "speed" covers three aspects, i.e., faster process, more work with same resources, and less FTE. In the interviews, FTE savings and faster processes were considered as two different effects. Most interviewees wanted to save FTE, but this did not necessarily mean that the process runs faster. Some explicitly stated that the speed of the bot does not matter at all as long as no person has to do the process anymore and the quality of the output is satisfying. Half of the interviewees expected improvements in result quality, an aspect being equally covered in literature. Improvements of compliance and availability are often emphasized in literature, but seem to be less important in practice according to the interviews. Though RPA is - per definition - a temporary solution [2], some RPA professionals consider it as a permanent one.

Neither literature nor practice focuses on the monitoring of RPA bots (RQ 2). The interviews emphasized that it is important that the bot works, whereas the exact effects are less interesting. Some interviewees confirmed that they "want to be first" meaning they wanted to be the first ones implementing and introducing an RPA bot in the company. Accordingly, monitoring the effects of the bot is not important to them. Reference [20] investigates benefits of applying RPA to master data management in two companies. However, the benefits are only qualified, but not quantified. As a result, in both cases quality and productivity are improved. Moreover, human errors, transaction time, and costs are reduced, and employees are relieved from repetitive tasks. Details on how the data are gathered are missing. Reference [28] presents a structured literature review identifying RPA benefits while stating that "future research on RPA benefits realisation" constitutes a challenge to be tackled.

Concerning RQ 3, the developed measures are a first step towards quantifying RPA effects. Still, other measures are useful, for example, FTE savings can be measured more precisely by subtracting the time needed to trigger the bot and necessary manual rework if the bot makes an error. A faster process execution can be measured by different aspects like, e.g., the service and waiting times, i.e., the time spent by resources on process execution and the idle time of a case (e.g., [22] measures the effectiveness of workflow management systems).

In the following, results concerning RQ 4 (i.e., whether or not the expected RPA effects were achieved) are discussed and related to the effects expected according to the interview results.

All projects save FTE. Although I12 did not mention FTE savings, P12 saves 1.43 FTE. I08 stated that FTE savings are not the prior focus of introducing RPA, still 0.07 FTE are saved in P08. Low FTE savings are due to a small number of process transactions and/or a short case duration.

Improvements of result quality are not granted. Only nine of the twelve projects achieve at least slight quality 


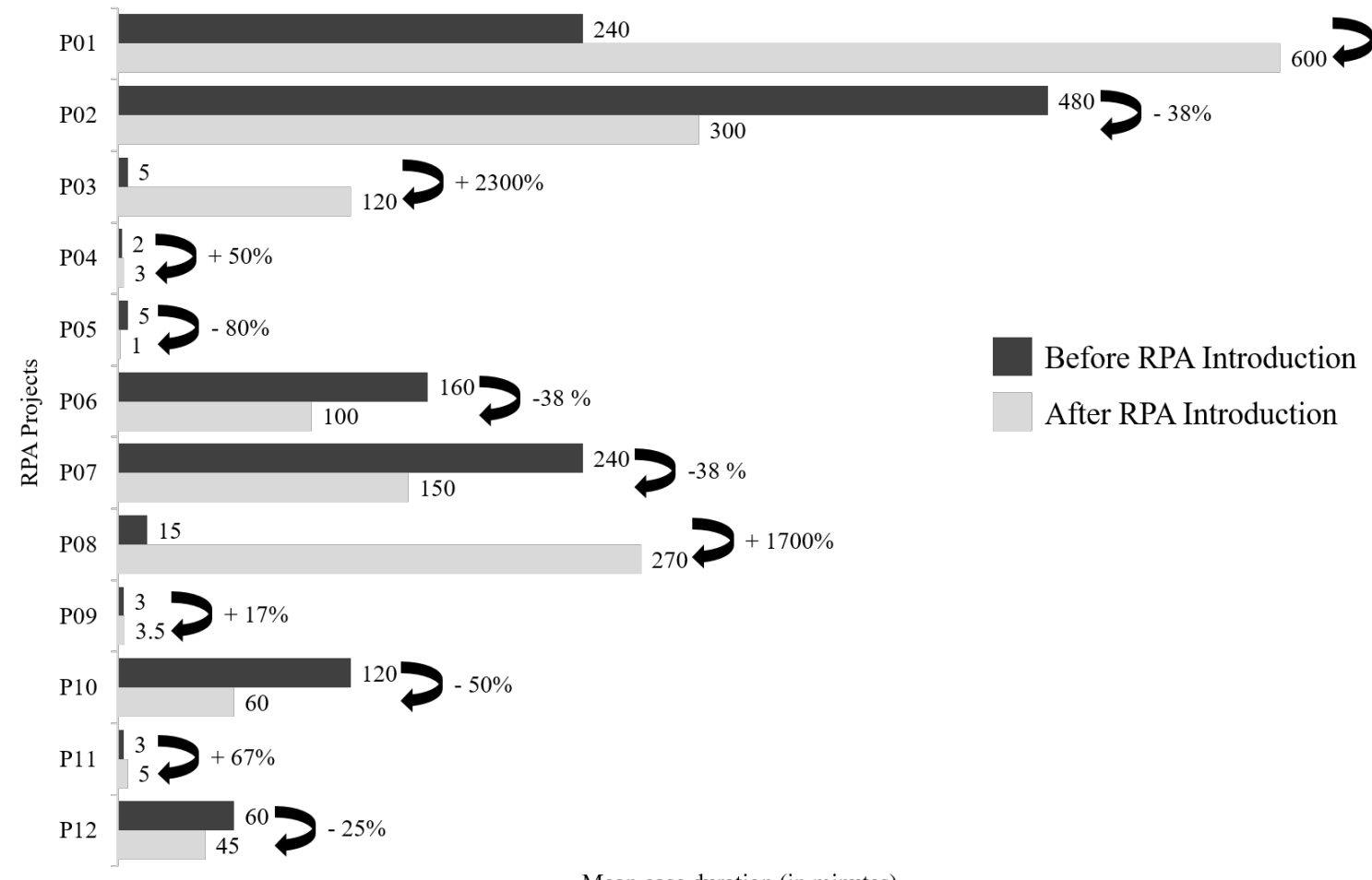

Mean case duration (in minutes)

Fig. 4. Mean case duration in minutes before and after RPA introduction and percentage change per project.

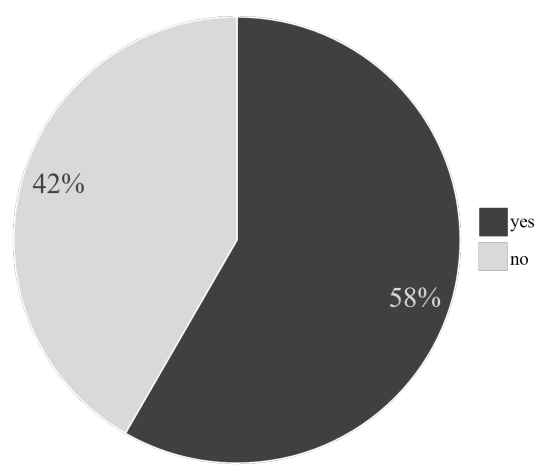

Fig. 5. Is RPA a temporary solution?

improvements. No project manages $99.99 \%$ of accuracy as reported in [31]. The best improvements are achieved in P05 and $\mathrm{P} 09$, which both constitute projects with a high number of process executions (50 respectively 200 cases per day). Obviously, human process execution is error prone and an RPA bot helps to reduce human errors. Concerning P12, which suffers deteriorations in quality, the filled questionnaire indicates that the bot works perfectly, but the employees do not provide the correct input. Here, a training for the employees working with the bot would be a reasonable approach. In general, it would be interesting to understand why processes are prone to errors. Different root-causes seem plausible: the implementation is not correct, or the human input is not precise, or the process is too complex for a bot and human interaction becomes necessary. In the interviews, improvement of result quality was seen as an important aspect in P01-P04, $\mathrm{P} 09$, and P12. For the first five projects, a reduction of $40 \%$ up to $99 \%$ of the errors is achieved with RPA. Only P12 does not attain the expected improvement as employees have not always provided the correct input.

In [31], the speed of process execution is improved from days to minutes. None of the investigated project reaches such an improvement. Reference [32] improves the mean case duration from 360 to 15 minutes, leading to a $96 \%$ faster process by using RPA. The use case in [13] achieves a $30 \%$ faster process. Regarding Fig. 4, six of the investigated projects improve by $25 \%$ to $80 \%$ concerning the mean case duration of the automated process. Reference [1] presents a mean case duration improvement from 440 seconds to 431 seconds, which is an improvement of only around $2 \%$. Some of the studied projects slow down the mean case duration. Note that according to the interviews, a faster process is not always the focus (I02, I09, I11). As motivation, the interviewees mention that "no person has to execute the process anymore, no matter how long the bot takes." In contrast, I05, I08, and I13 wanted to speed up the process by RPA. Only P05 achieves this improvement with the process taking 5 minutes before and 1 minute after RPA introduction. Interestingly, P03 and P08 have a longer mean case duration with RPA. 
TABLE IV

OVERVIEW P03: ACHIEVED EFFECTS.

\begin{tabular}{|c|c|}
\hline $\mathbf{P 0 3}$ & $\begin{array}{l}\text { Bot generates reports with data from different systems } \\
\text { for communication to the customer. }\end{array}$ \\
\hline $\begin{array}{l}\text { Expected effects } \\
\text { (interview) }\end{array}$ & $\begin{array}{l}\text { FTE savings, improvement of result quality, faster } \\
\text { process }\end{array}$ \\
\hline FTE savings & 0.02 FTE \\
\hline Result quality & $\begin{array}{l}5 \% \text { of erroneous cases before RPA } \\
3 \% \text { of erroneous cases with RPA } \\
-40 \% \text { improvement }\end{array}$ \\
\hline Faster process & $\begin{array}{l}5 \text { minutes mean case duration before RPA } \\
120 \text { minutes mean case duration with RPA } \\
+2300 \% \text { deterioration }\end{array}$ \\
\hline
\end{tabular}

TABLE V

OVERVIEW P05: ACHIEVED EFFECTS.

\begin{tabular}{l|l}
\hline P05 & Bot assigns tasks to the responsible employee. \\
\hline $\begin{array}{l}\text { Expected effects } \\
\text { (interview) }\end{array}$ & $\begin{array}{l}\text { FTE savings, faster process, improvement of avail- } \\
\text { ability }\end{array}$ \\
\hline FTE savings & 0.6 FTE \\
\hline Faster process & 5 minutes mean case duration before RPA \\
& 1 minute mean case duration with RPA \\
& $-80 \%$ improvement \\
\hline Availability & $\begin{array}{l}\text { fixed working hours and absence times before RPA } \\
24 / 7 \text { availability with RPA }\end{array}$ \\
\hline Result quality & $\begin{array}{l}10 \% \text { of erroneous cases before RPA } \\
\text { (not expected) }\end{array}$ \\
& $\begin{array}{l}0.1 \% \text { of erroneous cases with RPA } \\
-99 \% \text { improvement }\end{array}$ \\
\hline
\end{tabular}

Finally, we assess the twelve projects on whether or not the expected effects were achieved with the respective RPA initiative. Tables IV and V present exemplary overviews of two projects (P03 and P05). Each table depicts the automated task, expected effects mentioned in the interviews, and concrete numbers for the actually achieved effects. P03 achieves minor FTE savings (0.02 FTE) and result quality is improved by $40 \%$. Before introducing RPA, $5 \%$ of the cases were error prone, and after RPA introduction 3\% of the cases are erroneous. The fastening of the process is not achieved as expected, the mean case duration deteriorates from 5 minutes to 120 minutes (cf. Table IV). By contrast, P05 constitutes a successful RPA initiative: 0.6 FTE are saved, the mean case duration improves by $80 \%$ from 5 minutes to 1 minute, and the expected improvement in respect to availability is achieved. Additionally, RPA improves result quality by $99 \%$ even though the effect was not expected beforehand (cf. Table V).

Table VI summarizes all projects as well as expected and achieved effects on a more abstract level. "+" and "“" indicate an expected or achieved positive respective negative effect, and " $"$ " indicates that the achieved effect is minimal (e.g. less than 0.1 FTE are saved). The concrete numbers can be retrieved from Figures 2-4.

Eight of the twelve RPA projects, i.e., P01, P02, P05-P07, and P09-P11, may be considered as successful achieving all effects expected beforehand. By contrast, $\mathrm{P} 03$ does not attain the expected FTE savings and speed effects, P04 does not fulfill the expected FTE savings, P08 does not improve in
TABLE VI

OVERVIEW OF EXPECTED AND ACHIEVED EFFECTS

\begin{tabular}{c|c|c|c|c|c|c}
\hline & \multicolumn{2}{|c|}{ FTE savings } & \multicolumn{2}{c|}{$\begin{array}{c}\text { Improvement } \\
\text { of result quality }\end{array}$} & \multicolumn{2}{c}{ Faster process } \\
\cline { 2 - 7 } & Expected & Achieved & Expected & Achieved & Expected & Achieved \\
\hline \hline P01 & + & + & + & + & & - \\
\hline P02 & & + & + & + & - & + \\
\hline P03 & + & $/$ & + & + & + & - \\
\hline P04 & + & $/$ & + & + & & - \\
\hline P05 & + & + & & + & + & + \\
\hline P06 & + & + & & $/$ & & + \\
\hline P07 & + & + & & - & & + \\
\hline P08 & - & + & & - & + & - \\
\hline P09 & + & + & + & + & - & - \\
\hline P10 & + & + & & + & & + \\
\hline P11 & + & + & & $/$ & - & - \\
\hline P12 & + & + & + & - & & + \\
\hline
\end{tabular}

speed as expected, and P12 does not attain better result quality.

The major lessons learned are as follows:

- FTE savings are the main expectation articulated when introducing RPA in a knowledge-intensive domain.

- A faster process is regarded as a positive side-effect of introducing RPA, but is not the main motivation.

- Expected effects are not always achieved.

- RPA effect measures should be further developed, as also emphasized in [28] that calls to research "comprehensive metrics for benefits" which we support.

As a thread to validity, the number of participants filling in the questionnaire is rather small, only RPA experts of one large company from the automotive domain participated. Nevertheless, insights into twelve different RPA projects from the automotive industry were gained, constituting a valuable contribution to the currently rather qualitative literature on RPA. The results further show that no general statement regarding the effects of an RPA implementation and introduction can be made.

\section{SUMMARY AND OUTLOOK}

The positive effects reported in literature cannot be taken for granted in RPA projects. Therefore, it is desirable to predict the effects of an RPA project beforehand, e.g., based on business process criteria. For this, many more RPA implementations need to be investigated, which could be part of future research.

For future RPA projects the effects to be achieved should be explicitly defined at the beginning. Accordingly, the current not yet automated - business process can be measured to these effects. After implementing and introducing RPA, the same effects are measured and it is monitored whether the expected effects are accomplished. For example, sometimes a faster process is not necessarily expected, therefore, the measure of the mean case duration needs not be evaluated. Hence, an RPA project can be successful even if general measures do not indicate the success. 


\section{REFERENCES}

[1] S. Aguirre and A. Rodriguez, "Automation of a Business Process Using Robotic Process Automation (RPA): A Case Study," in Workshop on Eng Appl. Springer, 2017, pp. 65-71.

[2] A. Asatiani and E. Penttinen, "Turning robotic process automation into commercial success - Case OpusCapita," J Inf Technol Teach Cases, vol. 6, no. 2, pp. 67-74, 2016.

[3] A. Asquith and G. Horsman, "Let the robots do it! - Taking a look at Robotic Process Automation and its potential application in digital forensics," Forensic Science International: Reports, vol. 1, 2019.

[4] J. Bruno, S. Johnson, and J. Hesley, "Robotic disruption and the new revenue cycle: robotic process automation represents an immediate new opportunity for healthcare organizations to perform repetitive, ongoing revenue cycle processes more efficiently and accurately," Healthc Financ Manag, vol. 71, no. 9, pp. 54-62, 2017.

[5] T. R. Eikebrokk and D. H. Olsen, "Robotic Process Automation and Consequences for Knowledge Workers; a Mixed-Method Study," in Conf e-Business, e-Services e-Society. Springer, 2020, pp. 114-125.

[6] D. Fernandez and A. Aman, "Impacts of Robotic Process Automation on Global Accounting Services," Asian J Account Gov, vol. 9, pp. 123-132, 2018.

[7] H. P. Fung, "Criteria, Use Cases and Effects of Information Technology Process Automation (ITPA)," Adv Robot Autom, vol. 3, no. 3, 2014.

[8] J. Geyer-Klingeberg, J. Nakladal, and F. Baldauf, "Process Mining and Robotic Process Automation: A Perfect Match," in BPM (Dissertation/Demos/Industry, 2018, pp. 124-131.

[9] P. Hallikainen, R. Bekkhus, and S. L. Pan, "How OpusCapita Used Internal RPA Capabilities to Offer Services to Clients," MIS Q Exec, vol. 17, no. 1, pp. 41-52, 2018.

[10] J. Hindel, L. M. Cabrera, and M. Stierle, "Robotic process automation: Hype or hope?" in WI2020 Zentrale Tracks, 2020, pp. 1750-1762.

[11] C. Houy, M. Hamberg, and P. Fettke, "Robotic Process Automation in Public Administrations," in Digitalisierung von Staat und Verwaltung, M. Räckers, S. Halsbenning, D. Rätz, D. Richter, and E. Schweighofer, Eds. Gesellschaft für Informatik eV, 2019, pp. 62-74.

[12] M. Jørgensen, "A review of studies on expert estimation of software development effort," J Syst Softw, vol. 70, pp. 37-60, 2004.

[13] M. Lacity and L. Willcocks, "A New Approach to Automating Services," MIT Sloan Manag Rev, 2017.

[14] M. Lacity, L. Willcocks, and A. Craig, "Robotic process automation at Xchanging," Outsourcing Unit Work Pap Ser, vol. 15, no. 3, pp. 1-26, 2015.

[15] - "Robotizing Global Financial Shared Services at Royal DSM," Outsourcing Unit Work Pap Ser, vol. 16, no. 2, pp. 1-26, 2016.

[16] —- "Service Automation: Cognitive Virtual Agents at SEB Bank," London Sch Econ Polit Sci, pp. 1-29, 2017.

[17] V. Leno, M. Dumas, F. M. Maggi, and M. La Rosa, "Multi-Perspective process model discovery for robotic process automation," in CEUR Workshop Proceedings, vol. 2114, 2018, pp. 37-45.

[18] M. Lohrmann and M. Reichert, "Understanding business process quality," in Bus Process Manag, M. Glykas, Ed. Springer, 2013, vol. 444, pp. 41-73.

[19] S. Mohanty and S. Vyas, "Intelligent Process Automation = RPA + AI," in How to Compete in the Age of Artificial Intelligence. Apress, Berkeley, CA, 2018, pp. 125-141.

[20] A. M. Radke, M. T. Dang, and A. Tan, "Using Robotic Process Automation (RPA) to enhance item master data maintenance process," LogForum, vol. 16, no. 1, pp. 129-140, 2020.

[21] M. Reichert and B. Weber, Enabling flexibility in process-aware information systems: challenges, methods, technologies. Springer Science \& Business Media, 2012.

[22] H. A. Reijers, I. Vanderfeesten, and W. M. Van Der Aalst, "The effectiveness of workflow management systems: A longitudinal study," Int J Inf Manag, vol. 36, no. 1, pp. 126-141, 2016.

[23] M. Schmitz, C. Dietze, and C. Czarnecki, "Enabling digital transformation through robotic process automation at Deutsche Telekom," in Digitalization Cases, Management for Professionals, N. Urbach and M. Röglinger, Eds. Springer, 2019, pp. 15-33.

[24] M. Schmitz, C. Stummer, and G. Michael, "Smart Automation as Enabler of Digitalization? A Review of RPA/AI Potential and Barriers to Its Realization," in Future Telco, Management for Professionals, P. Krüssel, Ed. Springer, 2019, pp. 349-358.
[25] M. Smeets, R. Erhard, and T. Kaußler, "Robotic Process Automation (RPA) in der Finanzwirtschaft," Springer Books, 2019.

[26] V. K. Suri, M. Elia, P. Arora, and J. van Hillegersberg, "Automation of Knowledge-Based Shared Services and Centers of Expertise," in Digital Services and Platforms, Considerations for Sourcing, Global Sourcing, Lecture Notes in Business Information Processing, J. Kotlarsky, I. Oshri, and L. Willcocks, Eds. Springer, 2018, vol. 344.

[27] V. K. Suri, M. Elia, and J. van Hillegersberg, "Software bots - The next frontier for shared services and functional excellence," in Global Sourcing of Digital Services: Micro and Macro Perspectives, Global Sourcing, Lecture Notes in Business Information Processing, I. Oshri, J. Kotlarsky, and L. Willcocks, Eds., vol. 306. Springer, 2017, pp. 81-94.

[28] R. Syed, S. Suriadi, M. Adams, W. Bandara, S. J. Leemans, C. Ouyang, A. H. ter Hofstede, I. van de Weerd, M. T. Wynn, and H. A. Reijers, "Robotic Process Automation: Contemporary Themes and Challenges," Comput Ind, vol. 115, 2020.

[29] J. Wewerka and M. Reichert, "Robotic process automation - a systematic literature review and assessment framework," Enterp Inf Sys, submitted for publication.

[30] L. Willcocks and M. Lacity, "Robotic Process Automation: The Next Transformation Lever for Shared Services," Outsourcing Unit Work Pap Ser, vol. 15, no. 7, pp. 1-35, 2015.

[31] - "Robotic Process Automation at Telefónica O2," MIS Q Exec, vol. 15, no. 1, pp. 21-35, 2016.

[32] W. William and L. William, "Improving Corporate Secretary Productivity using Robotic Process Automation," Proc - 2019 Int Conf Technol Appl Artif Intell TAAI 2019, 2019.

[33] A. Wróblewska, T. Stanisławek, B. Prus-Zajạczkowski, and Ł. Garncarek, "Robotic Process Automation of Unstructured Data with Machine Learning," Ann Comput Sci Inf Syst, vol. 16, pp. 9-16, 2018

\section{APPENDIX - QUESTIONNAIRE}

In the following, the questionnaire used to survey data before and after introducing RPA can be found.

\section{Dear RPA Creator,}

Thank you, for the time you took for the interview. I developed a questionnaire to measure the effects that were mentioned in the interviews and would be very happy if you take 2 minutes and fill it out. Participation in the survey is voluntary. The results are scientifically evaluated. If you have any questions, I can be reached by email. If you would like to be informed about the results, please contact me.

Thanks for your support!

Put yourself in the situation before the process was supported by RPA and please answer the following questions. If your process did previously not exist in the current form, please provide estimates for questions 2-4.

1. Did your process exist in the current form before the RPA implementation?

$$
\mathrm{O} \text { Yes } \quad \mathrm{O} \text { No }
$$

2. The process was executed times a day by all employees. On average, an employee needed minutes.

3. An error occurred in approximately percent of the process executions.

4. Compliance guidelines were not complied with in around percent of the process executions.

The RPA bot is now running and supporting the process. Please answer the following questions. 
1. The bot runs _ a day and takes an average of minutes.

2. The bot is

$\mathrm{O}$ always available.

O not always available without any consequences on the process.

O not always available with consequences on the process. Consequences:

3. The bot throws an error in percent of the process execution and manual rework is necessary.

4. Is RPA planned to be a temporary solution? $\mathrm{O}$ Yes O No

Please provide a short description of your bot: 